\title{
The Lancet Global Health Academic Writing Workshop: Navigating and getting noticed in the scholarly publishing world
}

\author{
Daniel W. O'Neilla
}

${ }^{a} \mathrm{MD}, \mathrm{MA}(T h)$, Assistant Clinical Professor, Family Medicine, University of Connecticut School of Medicine, USA

Zöe Mullan, Editor-in-Chief, Lancet Global Health, and Audrey Ceschia, Editor, Lancet Public Health, presented a half-day preconference session on Thursday, March $15^{\text {th }} 2018$ prior to the $9^{\text {th }}$ Annual Consortium for Universities of Global Health Conference in New York City. There was also a follow-up webinar on the topic on Thursday, April $26^{\text {th }}$.

The publishing environment has significantly changed from that of only a few decades ago. Getting your research published, and published where it matters to you, your peers, and your university, requires skills and knowledge the academics of the last century could never have foreseen. The content of these seminars and some other sources will guide you through the challenges with insider tips and strategies from some experts in the field of publishing and journalism.

\section{The Process}

Getting your work published is a discipline that sharpens your work, builds collective knowledge for the common good, and inspires and fosters innovation. The peer review process can be intimidating but very rewarding. It starts with developing a research question or discovering a topic of interest to analyze from your field of work. Looking at problems in light of previous work and existing knowledge helps you design a relevant research endeavor. There is a spectrum of academic rigor, cost, and profile among traditional and openaccess journals from which to pursue publication.

\section{What Do Editors Look for in a Paper?}

Editors of top journals are looking for "an answer to a relevant question in an important population in the appropriate way at an opportune time." The following set of criteria is used when accepting papers for publication:

- Relevance: It must be within the scope of the journal and relevant to the audience of the journal.

- Novelty: It must express new treatments, new populations, new disease distribution, and new knowledge of the future (modelling). It does not simply state, "These findings confirm the work of..."

- Design: It should offer robust methodology with sufficient sample size (power), appropriate study design (controls, validation, assumptions), and some generalizability.

- Responsible Reporting: It should have ethics approval, informed consent, pre-registration for trials, and adherence to guidelines such as the Equator Network. ${ }^{1}$

- Definitiveness: It should have the last word, not necessarily a positive finding — relevant 
negatives are acceptable. It should not simply state, "More research is needed."

- Efficiency: It should avoid waste since $85 \%$ of research is a waste of time, money, and good will..$^{2,3}$

\section{Developing Research Questions}

Every good research endeavor starts with a systematic review of the literature before research design. The goal is to find a missing piece of the puzzle and pursue answers to important questions. The paper then explains how the findings add to useful knowledge. Every good paper tells a compelling story. If the paper is poorly written, or the story is not supported by the data, it will be rejected. Most editors welcome an e-mail with a proposal for a research project or paper, often 18-24 months prior to anticipated publication.

\section{Basic Paper Structure}

Research papers follow the IMRAD structure (Introduction, Methods, Results, and Discussion). The introduction presents the problem, what is published, and why research is needed. The method section describes exactly what was done, where, when, population, analysis, literature search method (if a review paper), and outcomes measured. The results only report on the findings of the research. The discussion gives the bottom line and what is next. In writing the manuscript, start with the data, then methods, conclusion, and introduction, then titles and abstract last.

\section{Title}

Informative but concise, the title must adequately describe content and study design, contain no technical jargon or abbreviations but only formal language, and attract the reader's attention.

\section{Abstract}

This should contain a single paragraph or two describing the article. This is often the only thing read. It is written last but read first. It must accurately reflect the paper, state the aim prominently, give enough detail to show what you did, and use flowing words so that it is easy to read even for the non-expert. Conclusions need to be backed up by evidence presented.

\section{Keywords}

Must be specific enough for indexing (discoverability for researchers), give readers a quick idea of content, and use only abbreviations firmly established in the field of study.

\section{Introduction}

This provides a brief context, summarizes previous research (based upon your own literature review), addresses the problem, identifies the solutions and limitations, outlines what your work is trying to achieve, and gives a perspective consistent with the nature of the journal.

\section{Methods}

This section describes how you studied the problem - not why but what. Include detailed information identifying the equipment and materials used (including literature search methods for review articles). It must contain ethics committee approval (Institutional Review Board [IRB]) and follow the Helsinki Declaration on studies involving human subjects. ${ }^{4}$ All methods need results. The EQUATOR Network gives valuable structure for different research methods. ${ }^{5}$

\section{Results}

Only present data of primary importance, use subheadings, be clear and concise, feature unexpected findings and highlight the main findings, provide statistical analysis, and include illustrations and figures that are not too crowded. Images need to have clear resolution and have scale markers. This section does not interpret the data, just presents the results.

\section{Discussion}

Here the main findings can be summarized and interpreted. Not just a repetition of results but an assessment of them. Discuss relevance to prior work and how your results correspond to them. Mention limitations (before reviewers point them out!), mention strengths, and do not present findings not 
mentioned in the results section. Do not make claims that are not supported by the results. Do not use nonspecific expressions or new terms not already defined or mentioned in the paper, and do not speculate on possible interpretations based on imagination. Finish with implications for implementation.

\section{Conclusion}

The conclusion consists of concise statements that need to be clear and justify your work, not just a verbatim repetition of the abstract. It explains how your work advances the present state of knowledge and offers suggestions for future research.

\section{Acknowledgements}

Here one would recognize advisors, sources of financial support, suppliers of research materials, proof readers, assistants, etc...

\section{References}

Do not include too many references (especially if only tangentially related), and fully absorb the material you are referencing. Avoid excessive selfcitations or citations from the same author, institution, or region. Reputable peer-reviewed references are preferred. Conform to the reference style given in the Author Guidelines of the journal.

\section{Supporting material}

These are surveys, data tables, and other supplemental information relevant to the study, but not required to be included in the body of the paper.

The EQUATOR Network gives vital links to reporting guidelines for every type of health-related research article, ${ }^{5}$ and the STROBE checklist can be used in planning and reporting observational studies. ${ }^{6}$

\section{Choosing a Journal}

In order to get the widest readership and citation among the target audience you wish to influence, a reputable journal that encompasses your content in its scope should be chosen. Open access publishing offers significant advantages for discoverability and global reach. ${ }^{7}$ Making research results more accessible contributes to better and more efficient science and to innovation in the public and private sectors, especially in low- and middleincome countries. However, advantages and disadvantages need to be considered. ${ }^{7}$ Indexing in the Directory of Open Access Journals and PubMed Central indicates reputability. Caution should be taken to avoid predatory journals. ${ }^{9}$ A checklist is available for researchers to identify trusted journals for publication. ${ }^{10}$

\section{Publication Ethics}

Membership in the Committee on Publication Ethics (COPE) ensures publication ethics. ${ }^{11}$ Ms. Mullan noted that $58 \%$ of researchers were aware of others who were tempted to compromise, $26 \%$ were tempted themselves, and $31 \%$ felt rushed to publish. She described the "staircase of misconduct" from error to misconduct to fraud (fabrication, falsification, and plagiarism [figures and text without accreditation]). Authors must use quotations for verbatim quotes and avoid "text-recycling" (selfplagiarism). Authorship should follow the ICMJE definition: Substantial design, writing, approval, and agreement to be accountable to all aspects of the work $^{12}$ - no "gifts or ghosts." Authors must declare any conflicts of interest (e.g., Author of [retracted] 1998 MMR vaccine - autism study in Lancet did not disclose he was funded by parents suing the vaccine manufacturer). There is also peer-review misconduct - use of confidential information for personal benefit, not declaring competing interest, or patently faking peer reviews.

\section{Key Points in Research and Writing}

- Always consider, "What is the point?"

- Tell a compelling story.

- Checklists are your friends (reporting guidelines).

- Do not worry about perfect English, but it must be understood. 
- Choose a journal wisely (and follow information for authors).

- Focus on rigor, relevance, and ethical responsibilities.

\section{Further Resources}

AuthorAid has a mentorship program for developing country and emerging researchers. ${ }^{13}$ Mendeley is a free resource to manage references, organize papers, and network with other researchers. $^{14}$ Elsevier's Research Academy provides guidelines and educational tips for researchers. ${ }^{15}$ In addition to these resources mentioned in the workshop, WHO Regional Office in the Eastern Mediterranean produced a Practical Guide for Health Researchers, including a section on writing and publishing a scientific paper. ${ }^{16}$ Research4life is "designed to enhance the scholarship, teaching, research and policy-making of the many thousands of students, faculty, scientists, and medical specialists, focusing on Health, Agriculture, Environment and other life, physical and social sciences in the developing world, through free or low-cost access to academic and professional peer-reviewed content online." 17

\section{References}

1. EQUATOR Network. Enhancing the QUAality and Transparency Of health Research. Available from: http://www.equator-network.org/

2. Chalmers I, Glasziou P. Avoidable waste in the production and reporting of research evidence. Lancet. 2009;374:86-9. https://doi.org/10.1016/S0140-6736(09)60329-9

3. Chinnery F, Kelly MD, van der Linden B, Westmore M, Whitlock E. Ensuring value in health-related research. The Lancet. 03 Mar 2018;391(10123): 8367. https://doi.org/10.1016/S0140-6736(18)30464-1

4. WMA Declaration of Helsinki - Ethical principles for medical research involving human subjects. World Medical Association. Available from: https://www.wma.net/policies-post/wma-declarationof-helsinki-ethical-principles-for-medical-researchinvolving-human-subjects/
5. EQUATOR Network. Enhancing the QUAlity and transparency of health research. Available from: http://www.equator-network.org/

6. Vandenbroucke JP, von Elm E, Altman DG, Pocock SJ, Gøtzscheet PC, Vandenbroucke JP. Strengthening the reporting of observational studies in epidemiology (STROBE): Explanation and elaboration. PLoS Medicine. 2007;4(10):e297. https://doi.org/10.1371/journal.pmed.0040297

7. Carroll MW. Creative commons and the openness of open access. N Engl J Med. 2013;368:789-91. https://doi.org/10.1056/NEJMp1300040

8. Open Access.nl. Pros and cons. Available from: http://openaccess.nl/en/what-is-open-access/pros-and$\underline{\text { cons }}$

9. Clark J, Smith R. Firm action needed on predatory journals. BMJ. 2015;350:h210. https://doi.org/10.1136/bmj.h210 [See also: Identifying predatory journals. World Association of Medical Editors. 18 Feb 2017. Available from: http://www.wame.org/identifying-predatory-orpseudo-journals]

10. Think, Check, Submit. Choosing the right journal for your research. Available from: https://thinkchecksubmit.org/about/

11. Committee on Publication Ethics. Available from: https://publicationethics.org/about

12. International Committee of Medical Journal Editors. Defining the role of authors and contributors.

Available from:

http://www.icmje.org/recommendations/browse/rolesand-responsibilities/defining-the-role-of-authors-andcontributors.html

13. AuthorAid. Available from: http://www.authoraid.info/en/

14. Mendeley: Your Reference Manager. Elsevier. Available from: https://www.mendeley.com/

15. Research Academy. Elsevier. Available from: https://researcheracademy.elsevier.com/learn

16. Fathalla MMF. A practical guide for health researchers. WHO Regional Office for the Eastern Mediterranean. Cairo 2004. Available from: http://www.who.int/ethics/reviewcommittee/emro_ethics dsa237.pdf

17. Research for Life. Access to Research in the Developing World. Available from: https://www.research4life.org/ 
Competing Interests: None declared.

Correspondence: Daniel W O'Neill, Christian Journal for Global Health and University of Connecticut School of Medicine, United States of America. dwoneill@cjgh.org

Cite this article as: O'Neill D W. The Lancet Global Health Academic Writing Workshop: Navigating and getting noticed in the scholarly publishing world. Christian Journal for Global Health. Sep 2018; 5(2):52-56.

(C) O'Neill D W. This is an open-access article distributed under the terms of the Creative Commons Attribution License, which permits unrestricted use, distribution, and reproduction in any medium, provided the original author and source are properly cited. To view a copy of the license, visit http://creativecommons.org/licenses/by/4.0/

\section{www.cjgh.org}

Sep 2018. Christian Journal for Global Health 5(1):52-56. 